\title{
3 Research Suare

\section{Determinants of Severe Acute Malnutrition Among Under 5 Children in Satar Community of Jhapa, Nepal}

Kajol Dahal ( $\square$ kajol.dahal09@gmail.com )

BP Koirala Institute of Health Sciences https://orcid.org/0000-0002-1930-8246

Deepak Kumar Yadav

BP Koirala Institute of Health Sciences

Dharanidhar Baral

BP Koirala Institute of Health Sciences

Birendra Kumar Yadav

BP Koirala Institute of Health Sciences

\section{Research}

Keywords: Severe acute malnutrition, Satar community, Household food insecurity

Posted Date: April 23rd, 2020

DOI: https://doi.org/10.21203/rs.3.rs-22946/v1

License: (c) (i) This work is licensed under a Creative Commons Attribution 4.0 International License. Read Full License 


\section{Abstract}

Background: Severe acute malnutrition is the most extreme and visible form of undernutrition plagued by chronic poverty, household food insecurity, lack of education. One of the indigenous and marginalized community of Nepal, Satar/Santhal has often been neglected and is devoid of good education and are economically deprived. This predisposes under 5 children of Satar into malnutrition. The study aims to assess determinants of SAM among children under 5 years of age in Satar community of Jhapa district, Nepal.

Material \& Methods: A community based matched case control study was carried from September 2019 to February 2020 among under five children of Satar community residing in Jhapa district. Multistage random sampling technique was used to select 50 cases and 100 controls in the ratio of 1:2. Information was collected through personal interview with the parents and anthropometric measurement of the children was measured. Bivariate and multivariate conditional logistic regression analysis was to explore the determinants of severe acute malnutrition.

Results: A total of 664 children between the age group of $6-59$ months were screened for SAM. The prevalence of SAM was found $7.53 \%$. Factors like, low economic status, birth interval less than 2 years, frequency of breast feeding $<8$ times/day and household food insecurity were found to be significant determinants of SAM. Multivariate logistic regression documented low economic status (AOR: 11.14, 95\% $\mathrm{Cl} 1.42$ to 87.46 ); and frequency of breast feeding $<8$ times/day (AOR: $2.09,95 \% \mathrm{Cl} 1.00$ to 4.37 ) as determinants of SAM.

Conclusion: Low economic status and frequency of breast feeding less than 8times/day were major determinants of SAM among children under 5yrs of age. Ending malnutrition will require greater efforts and integrated approaches to eradicate extreme poverty. Multi-sector approaches have been conducting for SAM in Nepal but there are no specific approaches for marginalized community.

\section{Background}

Malnutrition (mainly undernutrition) is a multifaceted problem especially for developing countries. Severe acute malnutrition is the most extreme and visible form of undernutrition, also called severe wasting, caused not from emergencies but plagued by chronic poverty, household food insecurity, lack of education [1, 2]. Specifically for acute malnutrition, severely wasted children have been estimated to have a greater than nine fold increased risk (relative risk of 9.4) of dying compared to a well-nourished child [3]. Around $45 \%$ of deaths among children under 5 years of age are linked to under nutrition, these mostly occur in low and middle-income countries [4]. Across the globe, an estimated 17 million children under the age of 5 are affected by severe acute malnutrition [2]. Asia is home to the largest number of children under 5 years of age with SAM, Asia together have more than 12 million children suffering from SAM [5].

All forms of malnutrition accounts for more than 50 per cent of child mortality in Nepal based on WHO estimates. And wasting prevalence is at a critical level in Nepal, affecting an estimated 430,000 children 
under five years of age at any point in time [6]. As per NDHS 2011, 2.6 per cent under-five year old children in Nepal are suffering from SAM [7]. Evidence has showed among many risk factors, (like low socioeconomic status, parental educational level, feeding practices) household food insecurity is also another very important and less talked factor determining SAM in Nepal $[8,9,10]$. Nepal ranked 60th out of 79 countries, where $52 \%$ households are food insecure [11].

There is a problem of malnutrition in general population, but the problem in indigenous people is worse. The Santhal (Satar) community is one of the most excluded ethnic groups in Nepal [12]. This vulnerable and indigenous community of Nepal has often been neglected and usually deprived of good education and utilization of health facilities [13-15].

There are studies done in West Bengal, India which has found that health and nutritional standards of children in Santhal community remain to be unsatisfactory [16-18]. It is evident that there is paucity of studies conducted in Nepal reflecting the possible predictors that predisposes the under 5 children of Satar community to SAM. Also, such studies are important for designing and implementing need based public health interventions centered on public health priority. Therefore, the study aims to assess the determinants of severe acute malnutrition (SAM) among children under 5 years of age in Satar community of Jhapa district, Nepal.

\section{Methods}

\section{Design and Sample}

This was a community based matched case-control study. The sample comprised 50 cases and 100 controls children from Satar community aged between 6 months to 59 months. To find 50 cases 664 children were screened. Children below five years from Satar (Santhal) community residing in Jhapa district of Nepal whose guardian gave consent were included in our study. The cases were the severely acute malnourished children below the age of 5 years ascertained by using the weight for height Z-score $<-3 S D$ below the median according to WHO 2006 growth standard and the controls were sex and agematched children aged 6-59 months from same community without malnutrition [19]. Those children whose guardian refused to provide consent or were not willing to participate in the study and children who were severely ill or were with co-morbidities were also excluded from the study.

\section{Study Duration And Selection Of Participants}

The study duration was from September 2019 to February 2020. The sample size was calculated assuming the prevalence of controls who were bottle fed at $18 \%$ with an odd ratio (OR) of 4.56 from the study in Bara, Nepal [20]. As this study considered $5 \%$ significance $(a=0.05)$ and $90 \%$ power to determine the sample size using formula for case control study, 


\section{$\underline{\left\{Z_{\frac{\alpha}{2}} \sqrt{(2 \overline{\mathrm{p}} \overline{\mathrm{q}})}+Z_{\beta} \sqrt{\left(p_{1} q_{1}+p_{2} q_{2}\right)}\right\}^{2}}$ \\ $\left(p_{1}-p_{2}\right)^{2}$}

The sample size calculated for each group was 43 children. Since the ratio of selecting cases and controls was $1: 2$ and after adding $10 \%$ non-response rate overall 50 cases and 100 controls samples were finalized. Multi-stage sampling technique was done. First, the Jhapa district was purposively selected. It consists of 8 urban and 7 rural municipalities. An indigenous group of Satar population was extracted from each municipality according to Central Bureau of Statistics, 2011 report. Among these fifteen municipalities of Jhapa District four municipalities were selected randomly, which consist of two urban and two rural areas. In these municipalities, anthropometric measurements (weight and height) of the children aged 6-59 months were taken and compared with WHO 2006 simplified growth standards to categorize the children as a case (weight for height <-3SD) or a control (weight for height >-2SD).

The cases and controls were matched in a $1: 2$ ratio with similar age intervals of $(6-8,9-12,12-14,15-$ $17,18-20,21-23,24-26,27-29,30-32,33-35,36-38,39-41,42-44,45-47,48-50,51-53,54-56$, and 57-59) months and sampling frames of cases or controls were prepared for each municipality. The sample population was screened unless 50 cases of severe acute malnutrition were found and the required controls were randomly selected from the sampling frames through simple random technique. Only one younger child was selected per household during data collection.

\section{Questionnaire}

A semi-structured questionnaire was developed. The questionnaire includes age and sex of a child, religion of the family, mother's educational level, father's educational level, maternal age at the time of delivery, family size, economic status and birth interval, colostrum feeding, initiation of breast feeding, exclusive breast feeding, initiation of complementary feeding, frequency of breast feeding, bottle feeding. Food insecurity was evaluated using the validated Household Food Insecurity Access Scale (HFIAS).

HFIAS: In this study, household food insecurity was assessed using Household Food Insecurity Access Scale (HFIAS) developed by the Food and Nutrition Technical Assistance (FANTA) project. The questionnaire consists of nine occurrence questions that represent a generally increasing level of severity of food insecurity (access), and nine "frequency-of-occurrence" questions that are asked as a follow-up to each occurrence question to determine how often the condition occurred. The frequency-of-occurrence question is skipped if the respondent reports that the condition described in the corresponding occurrence question was not experienced in the previous four weeks. Some of the nine occurrence questions inquire about the respondents' perceptions of food vulnerability or stress (e.g., did you worry that your household would not have enough food?) and others ask about the respondents' behavioral responses to insecurity 
(e.g., did you or any household member have to eat fewer meals in a day because there was not enough food?). The questions address the situation of all household members [21].

Date of Birth: Majority of the mothers of under 5 children in indigenous community of Satar were unable to show child health card or birth certificate for verifying date of birth. Therefore, the date of birth of the child was asked and its validity was verified through sibling method (birth order of child), local fist and festival calendar. The reliability was checked with other supportive questions like age of mother at pregnancy, and age of mother at present.

\section{Assessment Of Anthropometric Measurements}

Weight and recumbent length/height of the children were taken during daytime and were conducted for the 3 times to finalize the final measurement to record.

Height measurement: If a child was less than 2 years old, recumbent (lying down) length was measured. If the child was aged 2 years or older and was able to stand, standing height was measured. The height measurement was taken on flooring that was not carpeted and against a flat surface such as a wall. The child was measured without shoes, bulky clothing, hair ornaments, and unbraid hair that interfered with the measurement.

Weight measurement: A digital scale was used for the accurate measurement. The scale was placed on firm flooring (such as tile or wood). If the child was less than 2 years old or was unable to stand, the mother of that child was asked to stand on the scale along with her child in her arms. Then, the mother was asked to step on the scale to be weighed alone. She needed to adjust any long garments that covered the display. If the child was 2 or more than 2 years or was able to stand, he/she was asked to remove shoes and heavy clothing, such as sweaters. The children were asked to stand with both feet in the center of the scale and stand still, pointing their head firmly.

\section{Validity And Reliability}

Validity and reliability of the study was ensured by using Nepali translated semi-structured questionnaires and HFIAS used in NDHS 2016 [22]. Guide, co-guides and subject experts made necessary changes as per the suggestion from the departments. Furthermore, the questionnaire was pretested on 15 children ( 5 children with SAM and 10 children without SAM) which was $10 \%$ of the sample size. Pretesting was done in similar setting in Biratnagar, Nepal, and necessary correction was made in the questionnaire. During data collection, respondents were assured for confidentiality of information, and that will not be used other than the study purpose. The data was collected by investigator herself.

\section{Statistical analysis}


All interviewed questionnaire was indexed and kept in file. Master chart and coding list was prepared before entering the data. Collected data were entered into Microsoft Excel, 2007 and were converted into Statistical Package for Social Sciences (SPSS 11.5 version) for statistical analysis. Data were entered after every day's work, and were checked for validity.

All the numerical data variables were checked for normality using the Kolmogorov-Smirnov test, to assume parametric nature of the data. The independent t-test was used for parametric data. Descriptive statistics were conducted on demographic data collected. Bivariate and multivariate conditional logistics regression analysis was conducted to compare different characteristics between cases and controls taking the age group and sex matching into consideration. Statistical significance was tested with $95 \%$ confidence interval and $p<0.05$ was considered significant. Further to identify the strong predictors for determining SAM, confounders were adjusted by applying multi-collinearity diagnostic test between the independent variables before logistic regression was applied. Decisive criteria were set out to be a variance inflation factor (VIF) value of $>3$. The variables within the criteria were only used for logistic regression.

\section{Ethical Clearance:}

It was obtained from the Institutional Review Committee (IRC) of BPKIHS Nepal. The purpose of the study and the procedure was well explained and written informed consent was gained before starting the data collection. The participants were also informed that their participation was voluntary, and can withdraw at any moment. Moreover, they were assured regarding their anonymity, and the confidential treatment of their responses. All information were kept confidential, and the consent forms were number coded for identification.

\section{Results}

A total of 664 children, aged 6-59 months, were screened to find out 50 SAM cases, which accounted to the prevalence of $7.53 \%$ of SAM in indigenous community of Jhapa district.

Table 1 provides an overview of the age and sex of the sample, where maximum children with SAM were from the age group 6-17 months (40\%) and were female $56 \%$. Ninety-two percent of cases and $89 \%$ of controls families were Hindu. The illiteracy rate was higher among mothers of the cases $48 \%$ than the controls $32 \%$. In both the groups' paternal illiteracy rate was $34 \%$ among the cases and $26 \%$ in controls. The mean \pm SD ages of the mothers at the time of delivery of the cases and controls were $22.20 \pm 3.49$ and $21.87 \pm 3.53$ years respectively. And, the mean \pm SD number of family members of the cases and controls were $5.02 \pm 1.74$ and $4.64 \pm 1.40$ respectively.

In total there were $84 \%$ of families below poverty line (earning $<\$ 1.9 /$ day). Families accounted for below poverty line were $98 \%$ of cases and $77 \%$ of controls. Likewise, majority of the cases $20 \%$ were born in less than 2 years of birth interval compared to $8 \%$ of controls. 
Almost all, $92 \%$ of the cases and $93 \%$ of the controls were colostrum fed. In both the groups' breastfeeding was initiated immediately following birth i.e. within one hour in $80 \%$ of the cases and $70 \%$ of the controls. Lack of exclusive breastfeeding for the first six months of age was more common in the cases $98 \%$ than in the controls $94 \%$. More controls $33 \%$ were initiated with complementary feeding at 6 months of age than $22 \%$ of cases. Majority of the cases $54 \%$ were breastfed less than 8 times a day, compared with controls $30 \%$. Frequency of breast feeding was less in cases, if they had bottle feeding instead of nothing than the risk of developing SAM in cases could have been minimized. Only $26 \%$ of the cases in comparison to $31 \%$ controls were bottle fed.

The overall prevalence of household food insecurity access was $72 \%$. Majority $84 \%$ of the cases and twothird $(66 \%)$ of the controls were severely food insecure. Only $10 \%$ of the cases and nearly one-third of the controls were secured for food. 
Table 1

Description of socio-demographic characteristics of cases and controls

\begin{tabular}{|c|c|c|c|c|c|c|}
\hline \multirow[t]{2}{*}{ Characteristics } & \multicolumn{2}{|l|}{ Cases } & \multicolumn{2}{|c|}{ Controls } & \multicolumn{2}{|l|}{ Total } \\
\hline & $\mathrm{N}=50$ & $\%$ & $\mathrm{~N}=100$ & $\%$ & $N=150$ & $\%$ \\
\hline \multicolumn{7}{|l|}{ Age of the child } \\
\hline 6-17 months & 20 & 40.0 & 40 & 40.0 & 60 & 40.0 \\
\hline 18-29 months & 15 & 30.0 & 30 & 30.0 & 45 & 30.0 \\
\hline 30-41 months & 6 & 12.0 & 12 & 12.0 & 18 & 12.0 \\
\hline $42-53$ months & 3 & 6.0 & 6 & 6.0 & 9 & 6.0 \\
\hline 54-59 months & 6 & 12.0 & 12 & 12.0 & 18 & 12.0 \\
\hline \multicolumn{7}{|l|}{ Sex of the Children } \\
\hline Male & 23 & 46.0 & 46 & 46.0 & 69 & 46.0 \\
\hline Female & 27 & 54.0 & 54 & 54.0 & 81 & 54.0 \\
\hline \multicolumn{7}{|l|}{ Religion of the families } \\
\hline Hindu & 46 & 92.0 & 89 & 89.0 & 135 & 90.0 \\
\hline Christian & 4 & 8.0 & 11 & 11.0 & 15 & 10.0 \\
\hline \multicolumn{7}{|l|}{ Mother's Education Level } \\
\hline Illiterate & 24 & 48.0 & 32 & 32.0 & 56 & 37.3 \\
\hline Informal Education & 7 & 14.0 & 14 & 14.0 & 21 & 14.0 \\
\hline Primary Education & 11 & 22.0 & 26 & 26.0 & 37 & 24.7 \\
\hline Secondary Education & 5 & 10.0 & 20 & 20.0 & 25 & 16.7 \\
\hline SLC and Above & 3 & 6.0 & 8 & 8.0 & 11 & 7.3 \\
\hline \multicolumn{7}{|l|}{ Father's Education Level } \\
\hline Illiterate & 17 & 34.0 & 26 & 26.0 & 43 & 28.7 \\
\hline Informal Education & 11 & 22.0 & 13 & 13.0 & 24 & 16.0 \\
\hline Primary Education & 8 & 16.0 & 23 & 23.0 & 31 & 20.7 \\
\hline Secondary Education & 9 & 18.0 & 20 & 20.0 & 29 & 19.3 \\
\hline SLC and Above & 5 & 10.0 & 18 & 18.0 & 23 & 15.3 \\
\hline Mother's age at delivery (yrs) & 22.20 & \pm 3.49 & 21.87 & \pm 3.53 & 21.98 & \pm 3.5 \\
\hline No. of family members & 5.02 & \pm 1.74 & 4.64 & \pm 1.40 & 4.77 & \pm 1.5 \\
\hline
\end{tabular}




\begin{tabular}{|c|c|c|c|c|c|c|}
\hline \multicolumn{7}{|l|}{ Economic Status } \\
\hline Below Poverty Line & 49 & 98.0 & 77 & 77.0 & 126 & 84.0 \\
\hline Above Poverty Line & 1 & 2.0 & 23 & 23.0 & 24 & 16.0 \\
\hline \multicolumn{7}{|l|}{ Birth Interval } \\
\hline First Birth & 16 & 32.0 & 48 & 48.0 & 64 & 42.7 \\
\hline Less than 2 years & 10 & 20.0 & 8 & 8.0 & 18 & 12.0 \\
\hline More than 2 years & 24 & 48.0 & 44 & 44.0 & 68 & 45.3 \\
\hline \multicolumn{7}{|l|}{ Colostrum Feeding } \\
\hline Yes & 46 & 92.0 & 93 & 93 & 139 & 92.7 \\
\hline No & 4 & 8.0 & 7 & 7.0 & 11 & 7.3 \\
\hline \multicolumn{7}{|l|}{ Initiation of Breast Feeding } \\
\hline Within 1 hour of birth & 40 & 80.0 & 70 & 70.0 & 110 & 73.3 \\
\hline After 1 hour of birth & 10 & 20.0 & 30 & 30.0 & 40 & 26.7 \\
\hline \multicolumn{7}{|l|}{ Exclusive Breast Feeding } \\
\hline Done & 1 & 2.0 & 6 & 6.0 & 7 & 4.7 \\
\hline Not Done & 49 & 98.0 & 94 & 94.0 & 143 & 95.3 \\
\hline \multicolumn{7}{|c|}{ Initiation of Complementary Feeding } \\
\hline Before 6 months & 10 & 20.0 & 15 & 15.0 & 25 & 16.7 \\
\hline At 6 months & 11 & 22.0 & 33 & 33.0 & 44 & 29.3 \\
\hline After 6 months & 29 & 58.0 & 52 & 52.0 & 81 & 54.0 \\
\hline \multicolumn{7}{|l|}{ Frequency of Breast Feeding } \\
\hline$<8 /$ day & 27 & 54.0 & 30 & 30.0 & 57 & 38.0 \\
\hline$\geq 8 /$ day & 23 & 46.0 & 70 & 70.0 & 93 & 62.0 \\
\hline \multicolumn{7}{|l|}{ Bottle Feeding } \\
\hline Yes & 13 & 26.0 & 31 & 31.0 & 44 & 29.3 \\
\hline No & 37 & 74.0 & 69 & 69.0 & 106 & 70.7 \\
\hline \multicolumn{7}{|c|}{ Household Food Insecurity Access Category } \\
\hline Severely Food Insecure & 42 & 84.0 & 66 & 66.0 & 108 & 72.0 \\
\hline Moderately Food Insecure & 2 & 4.0 & 0 & 0.0 & 2 & 1.3 \\
\hline
\end{tabular}




\begin{tabular}{|lllllll|} 
Mildly Food Insecure & 1 & 2.0 & 2 & 2.0 & 3 & 2.0 \\
\hline Food Secure & 5 & 10.0 & 32 & 32.0 & 37 & 24.7 \\
\hline
\end{tabular}


Table 2

Association between severe acute malnutrition and variables among under five children in Satar community of Jhapa district $(n=150)$

\begin{tabular}{|c|c|c|c|c|c|c|}
\hline \multirow[t]{2}{*}{ Characteristics } & \multicolumn{2}{|l|}{ Cases } & \multicolumn{2}{|c|}{ Controls } & \multirow[t]{2}{*}{ COR $(95 \% \mathrm{Cl}) *$} & \multirow{2}{*}{$\mathrm{p}_{\text {Value* }}$} \\
\hline & $\begin{array}{l}\mathrm{n}=50 / \\
\text { mean }\end{array}$ & $\begin{array}{l}\% / \\
\text { SD }\end{array}$ & $\begin{array}{l}\mathrm{n}= \\
100 / \\
\text { mean }\end{array}$ & $\begin{array}{l}\% / \\
\text { SD }\end{array}$ & & \\
\hline $\begin{array}{l}\text { No. of family } \\
\text { members }\end{array}$ & 5.02 & 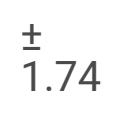 & 4.64 & \pm 1.40 & - & 0.168 \\
\hline \multicolumn{7}{|c|}{ Mother's Educational Level } \\
\hline Illiterate & 24 & 48.0 & 32 & 32.0 & $2.534(0.978-6.566)$ & 0.056 \\
\hline$\leq$ Primary Education & 18 & 36.0 & 40 & 40.0 & $1.560(0.609-4.002)$ & 0.354 \\
\hline $\begin{array}{l}\text { ZSecondary } \\
\text { Education }\end{array}$ & 8 & 16.0 & 28 & 28.0 & Ref & \\
\hline \multicolumn{7}{|l|}{ Economic Status } \\
\hline Below Poverty Line & 49 & 98.0 & 77 & 77.0 & $\begin{array}{l}13.103(1.732- \\
99.149)\end{array}$ & 0.013 \\
\hline Above Poverty Line & 1 & 2.0 & 23 & 23.0 & Ref & \\
\hline \multicolumn{7}{|l|}{ Birth Interval } \\
\hline Less than 2 years & 10 & 20.0 & 8 & 8.0 & $2.677(1.011-7.089)$ & 0.048 \\
\hline First birth or $>2$ years & 40 & 80.0 & 92 & 92.0 & Ref & \\
\hline \multicolumn{7}{|c|}{ Initiation of Complementary Feeding } \\
\hline$<6$ or $>6$ months & 39 & 78.0 & 67 & 67.0 & $1.782(0.808-3.932)$ & 0.153 \\
\hline At 6 months & 11 & 22.0 & 33 & 33.0 & Ref & \\
\hline \multicolumn{7}{|c|}{ Frequency of Breast Feeding (times) } \\
\hline$<8 /$ day & 27 & 54.0 & 30 & 30.0 & $2.612(1.282-5.321)$ & 0.008 \\
\hline$\geq 8 /$ day & 23 & 46.0 & 70 & 70.0 & Ref & \\
\hline \multicolumn{7}{|c|}{ Household Food Insecurity Access } \\
\hline Food Insecure & 45 & 90.0 & 68 & 68.0 & $\begin{array}{l}4.272(1.454- \\
12.549)\end{array}$ & 0.008 \\
\hline Food Secure & 5 & 10.0 & 32 & 32.0 & Ref & \\
\hline
\end{tabular}

The bivariate analysis showed that economic status, birth interval, frequency of breast feeding, and household food insecurity were significantly associated with SAM (Table 2). 
However, after the multivariate analysis, economic status and frequency of breast-feeding were found to be strong predictors of SAM (Table 3). The odd of having SAM was 11.14 folds more among the under 5 children of Satar/Santhal families who were below the poverty line than those who were above the poverty line (95\% Cl: 1.42-87.46). Similarly, children who were breastfed < 8times/day (AOR: $2.04,95 \% \mathrm{Cl}$ : 1.00-4.37) were more likely to suffer from SAM than those who were breastfed more than 8times per day.

Table 3

Multivariate Conditional Logistic Regression analysis to find out the determinants of severe acute malnutrition among the under five children in Satar community of Jhapa district $(n=150)$

\begin{tabular}{|c|c|c|c|c|}
\hline Characteristics & $\beta$ coefficient & COR(95\% Cl) & AOR(95\% Cl) & p Value \\
\hline \multicolumn{5}{|l|}{ Economic Status } \\
\hline Below Poverty Line & 2.410 & 13.103(1.732-99.149) & \multirow[t]{2}{*}{$11.139(1.419-87.456)$} & 0.022 \\
\hline Above Poverty Line & Ref & & & \\
\hline \multicolumn{5}{|c|}{ Frequency of Breast Feeding } \\
\hline$<8 /$ day & 0.738 & $2.612(1.282-5.321)$ & \multirow[t]{2}{*}{$2.093(1.003-4.368)$} & 0.049 \\
\hline$\geq 8 /$ day & Ref & & & \\
\hline
\end{tabular}

\section{Discussion}

The results of the multivariate conditional logistic regression indicate that economic status and frequency of breast feeding are the determinants of SAM for children who were under 5 years of age and were from the indigenous community, Satar/Santhal, of Jhapa district, Nepal.

The findings of the study revealed a prevalence of $7.53 \%$ of SAM which is in accordance to the study conducted in Sudan (6.5\%) and WHO prevalence of severe wasting in South East Asia in 2017(5\%) [23, 24]. However, the prevalence is higher in comparison to NDHS 2011 report where $2.6 \%$ of under-five year old children in Nepal are suffering from severe acute malnutrition (SAM) [7]. The high prevalence in our study might be due to the study population, Satar community, which is vulnerable and marginalized community of Nepal wherein the Santhal children are still devoid of good feeding practices, household food security and economic stability.

The study revealed that low economic status (below poverty line; earning $<\$ 1.9 /$ day)) was more than 11 folds at risk (AOR: 11.139 at $95 \% \mathrm{Cl}$ : 1.419-87.456) of developing SAM in children less than 5 years, which was statistically significant. The finding of our study is supported by the study done in Odisha of India, Bangladesh, and Ghana [25-27]. This could be explained by the fact that children from families of low socioeconomic status have limited access to food, health services, hygiene and sanitation. However, studies conducted in Illam, Nepal and Kenya showed that low economic status was not statistically significant with malnutrition $[28,29]$. 
Evidence from our study indicated that, children who were breast fed less than 8times/day were two folds more at risk of having SAM (AOR: 2.093 , at $95 \% \mathrm{Cl}$ : 1.003-4.368) which is in convergent to another case control study conducted in Nepal [20]. Likewise, a study in India documented that the risk of a child falling into the SAM category was found to reduce significantly with increasing frequency of breast feeding during exclusive breast feeding period [30]. In contrary to our finding, study from Ethiopia found no association between frequency of breast feeding and SAM [31].

UNICEF recommends to breastfeed your baby on demand, both day and night, at least 8 to 12 times each day [32]. The possible explanation for low frequency of breast-feeding might be that most of the Satar's families are below the poverty line which compels mother to work for daily earning. Therefore, the time spent at home of the mother affects breastfeeding frequency and babies do not get breast-fed whenever they desire for. Also, the lack of adequate nutrition in mothers limits sufficient milk production to feed their children as per requirement. And, many mothers are illiterate and lack knowledge regarding appropriate child feeding practices. These could be the possible reasons that revealed low frequency of breast-feeding as the determinant of SAM in our study.

\section{Conclusion}

Economic status and frequency of breast-feeding were found to be strong predictors of SAM, therefore, multi-faceted and multi-pronged strategies should be employed from government, stakeholders and political leaders to address the nutritional needs of deprived population. Children from low economic status have limited access to food and low frequency of breast-feeding reflects inadequate knowledge regarding child-feeding practices. Promotion of income generating activities, family planning for increasing the birth spacing and insuring food security through integrated approaches targeting the marginalized communities can serve as an early intervention measures to tackle the deep-rooted problem of SAM.

\section{Abbreviations}

AOR:Adjusted Odds Ratio, BPKIHS:B.P. Koirala Institute of Health Sciences, Cl:Confidence Interval, COR:Crude odds ratios, NDHS:Nepal Demographic and Health Survey, SAM:Severe Acute Malnutrition, SD:Standard Deviation, SLC:School Leaving Certificate, SPSS:Statistical Package for the Social Sciences, UNICEF:United Nations International Children's Emergency Fund, WHO:World Health Organization

\section{Declarations}

\section{Ethics approval and consent to participate:}

Consent was obtained from the participants of the study 


\section{Consent for publication:}

Consent of publication was obtained from the participants.

\section{Availability of data and materials:}

The datasets during and/or analysed during the current study are available from the corresponding author on reasonable request.

\section{Competing interests:}

The authors declare that they have no competing interests

\section{Limitation}

The study couldn't take into account other potential predictors of SAM like: immunization, environmental hygiene and sanitation, co-morbidities in children. Also, recall bias might have occurred in the study.

\section{Operational definitions}

Severe acute malnutrition: Ascertained by using the weight for height Z-score $<-3 S D$ below the median according to WHO 2006 growth standard.61

Household Food Insecurity: Household food insecurity was assessed using Household Food Insecurity Access Scale (HFIAS) developed by USAID under Food and Nutrition Technical Assistance (FANTA) project.62

Indigenous: Indigenous nationalities refer to those ethnic groups or communities who have their own mother tongue and traditional customs, different cultural identity, distinct social structure and written or oral history.22

Marginalized: Indigenous and ethnic groups that are largely facing the common problems of social exclusion, cultural discrimination and political oppression.23

\section{Competing interests:}

The authors declare that they have no competing interests.

\section{Funding:}




\section{Authors' contributions:}

$\mathrm{KD}$ analyzed and interpreted the participants' data regarding the socio-demography, feeding practices, anthropometric measurements and household insecurity data and was a major contributor in writing the manuscript. All the other authors read, made necessary changes, assisted in analysis, writing and approved the final manuscript.

\section{Acknowledgement}

We would like to that School of Public Health and Community Medicine, B.P. Koirala Institute of Health Sciences, Dharan, Nepal for allowing us to conduct this research under its banner. I would like to express my heartfelt gratitude to every individuals, respondents and institutions who had contributed for the completion of this research.

\section{References}

1. Lenters L, Wazny K, Bhutta ZA. Management of Severe and Moderate Acute Malnutrition in Children. In: Black RE, Laxminarayan R, Temmerman M, et al., editors. Reproductive, Maternal, Newborn, and Child Health: Disease Control Priorities. Third Edition (Volume 2). Washington (DC): The International Bank for Reconstruction and Development / The World Bank; 2016 Apr 5. Chapter 11. Available from: https:// www.ncbi.nlm.nih. gov/books/NBK361900/ doi: 10.1596/978-1-4648-0348-2_ch11

2. United Nations Children's Fund. Severe acute malnutrition [Internet].UNICEF:2015 Dec 23. https://www.unicef.org/nutrition/index_sam.html

3. Black RE, Allen LH, Bhutta ZA, Caulfield LE, de Onis M, Ezzati M, et al. Maternal and child undernutrition: global and regional exposures and health consequences. The Lancet. 2008 Jan;371(9608):243-60.

4. World Health Organization. Malnutrition Factsheet [Internet]. WHO: 2018 Feb 16. https://www.who.int/news-room/fact-sheets/detail/malnutrition

5. Ahmed T, Hossain M, Mahfuz M, Choudhury N, Hossain MM, Bhandari N, et al. Severe Acute Malnutrition in Asia. Food Nutr Bull. 2014 Jun;35(2_suppl1):S14-26.

6. Government of Nepal. Nepal Integrated Management of Acute Malnutrition(IMAM) Guideline. 2017. 7. Ministry of Health and Population (MOHP) [Nepal], New ERA, and ICF International Inc. Nepal Demographic and Health Survey. 2011.

8. Sreeramareddy $\mathrm{CH}$, Ramakrishnareddy N, Subramaniam MA. Association between household food access insecurity and nutritional status indicators among children aged $<5$ years in Nepal: results from a national, cross-sectional household survey. Public Health Nutrition. 2014;18(16):2906-2914. Available from: Doi: 10.1017/S1368980014002729

9. Motbainor AC, Worku AL, Kumie AB. Stunting is associated with food diversity while wasting with food 
insecurity among underfive children in East and West Gojjam Zones of Amhara Region, Ethiopia. PLoSONE. 2015;10(8):e0133542. Available from: Doi:10.1371/journal.pone.0133542

10. Ajao KO, Ojofeitimi EO, Adebayo AA, Fatusi AO, Afolabi OT. Influence of Family Size, Household Food Security Status, and Child Care Practices on the Nutritional Status of Under-five Children in Ile-Ife, Nigeria. African Journal of Reproductive Health. 2010 December;14(4):123.

11. International Food Policy Research Institute. 2012 Global Hunger Index. Washington, DC: IFPRI, 2012. 12. United Nations Resident and Humanitarian coordinator office. Field Bulletin state of Stateless Citizen: A case study on citizenship and landlessness issues of the Santhal Community 2011;5:5-6.

13. National Coalition Against Racial Discrimination (NCARD). Janajati Satar (Santhal). Anamnagar, Kathmandu, Nepal.https://www.ncard.org.np/ categorydetail/satar-santhal.html

14. Subedi BP. Demographic Situation of Satar/Santhal in Nepal (A Case of Surunga VDC, Jhapa, Nepal). 2014 May-June; 2(12). www.srjis.com

15. Adhikari K. Educational Status of Satar Community in the Perspective of Social Justice. 2012 16. Bisai, S. Prevalence of Undernutrition among Santal tribal Preschool Children of Paschim Medinipur District, West Bengal, India. International Journal of Pediatrics. 2014;2(4.3):347-354. doi:

10.22038/ijp.2014.3538

17. Ghosh JR, Sarkar A. Prevalence of undernutrition among Santal children of Birbhum District, West Bengal, India. Sri Lanka Journal of Child Health. 2013;42(3):147-150.

18. Mahapatra B, Dey J, Pal, S and Bose K. Prevalence of Under nutrition among Santal Preschool Children of Two Districts of West Bengal, India. Human Biology Review. 2019.8(2),179-196.

19. Coates J, Swindale A, Bilinsky P. Household Food Insecurity Access Scale (HFIAS) for Measurement of Food Access: Indicator Guide. Washington DC: Food and Nutrition Technical Assistance Project, Academy for Educational Development (FANTA); 2007 Aug.

20. Pravana NK, Piryani S, Chaurasiya SP, Kawan R, Thapa RK, Shrestha S. Determinants of severe acute malnutrition among children under 5 years of age in Nepal: a community-based case-control study. BMJ Open. 2017 Aug;7(8):e017084.

21. Coates J, Swindale A, Bilinsky P. Household Food Insecurity Access Scale (HFIAS) for Measurement of Food Access: Indicator Guide. Washington DC: Food and Nutrition Technical Assistance Project, Academy for Educational Development (FANTA); 2007 Aug.

22. Ministry of Health, Nepal, New ERA, ICF. Nepal Demographic and Health Survey 2016. Kathmandu, Nepal: Ministry of Health, Nepal. 2017.

23. Kanan $\mathrm{SOH}$, Swar MO. Prevalence and outcome of severe malnutrition in children less than ive-yearold in Omdurman Paediatric Hospital, Sudan. Sudanese Journal of Paediatrics. 2016;16(1).

24. United Nations Children's Fund, World Health Organization, International Bank for Reconstruction and Development, World Bank. Levels and trends in child malnutrition: key findings of the 2018 Edition of the Joint Child Malnutrition Estimates. Geneva: World Health Organization; 2018.

25. Jena P, Rath S, Nayak MK, Satapathy D. Study of social and demographic determinants of severe acute malnutrition in children aged 6-59 months in a tertiary care centre of Odisha, India.International Journal of Contemporary Pediatrics. 2019 Jan;6(1):46-51. DOI: http://dx.doi. org/10.18203/23493291.ijcp20185064 
26. Chowdhury MR, Rahman MS, Khan MM, Mondal MN, Rahman MM, Billah B. Risk factors for child malnutrition in Bangladesh: a multilevel analysis of a nationwide population-based survey. The Journal of Pediatrics. 2016;172:194-201. doi: 10.1016/j.jpeds.2016.01.023.

27. Tette EMA, Sifah EK, Nartey ET. Factors affecting malnutrition in children and the uptake of interventions to prevent the condition. BMC Pediatrics. 2015 Dec;15:189. DOI 10.1186/s12887-015-04963

28. Gaurav K, Poudel I, Bhattarai S, Pradhan P, Pokharel P. Malnutrition Status Among Under - 5 Children in a Hill Community of Nepal. Kathmandu University Medical Journal. 2015 Oct 19;12(4):264-8.

29. Abuya BA, Onsomu EO, Kimani JK, Moore D. Influence of maternal education on child immunization and stunting in Kenya. Maternal and Child Health Journal. 2011;15:1389-99. DOI: 10.1007/s10995-0100670-z.

30. Ambadekara NN, Zodpeyb SP. Risk factors for severe acute malnutrition in under-five children: a casecontrol study in a rural part of India. Royal Society for Public Health. 2017 Jan;142:136-143.

https://doi.org/10.1016/j.puhe.2016.07.018

31. Awoke A, Ayana M, Gualu T. Determinants of severe acute malnutrition among under five children in rural Enebsie Sarmidr District, East Gojjam Zone, North West Ethiopia, 2016. BMC Nutrition. 2018; 4(4). https://doi.org/10.1186/s40795-018-0211-5

32. United Nations International Children's Emergency Fund. How to Breastfeed your baby [Internet]. 2017 November 14. https://www.unicef.org/nutrition/files/Brochure_how_to_breastfeed.PDF 